\title{
LA REPRESIÓN FRANQUISTA DE GUERRA Y POSGUERRA EN EL PAÍS VASCO A DEBATE: ENTRE EL EXTERMINIO Y EL OASIS'
}

\section{Discussing postwar francoist repression in the Basque Country: Between extermination and oasis}

\author{
ERIK ZUBIAGA ARANA \\ Universidad del País Vasco / Euskal Herriko Unibertsitatea \\ Erik.zubiaga@gmail.com
}

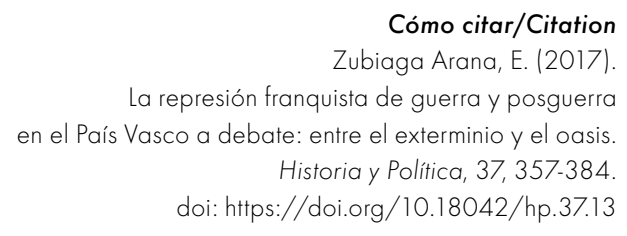

(Recepción: 01/09/2016. Evaluación: 09/10/2016. Aceptación: 14/10/2016. Publicación: 26/05/2017)

\section{Resumen}

El presente artículo versa sobre los debates que ha despertado la incidencia de la represión franquista de posguerra en el País Vasco. En primer lugar, se constata que el innegable avance de la historiografía académica en cuestiones referentes a la guerra y a la posguerra en Euskadi no ha impedido la fuerte implantación social de

1 Este trabajo forma parte de las investigaciones desarrolladas por el grupo de investigación del Sistema Universitario Vasco de Historia Social y Política del País Vasco Contemporáneo (IT-429-10), financiado por el Gobierno Vasco. Asimismo, es beneficiario de la convocatoria de contratación de doctores recientes hasta su integración en programas de formación postdoctoral en la UPV/EHU (2016). Agradezco a Luis Castells la atenta lectura del texto. 
tesis, ajenas al ambito académico, con claro perfil ideologico y repletas de tópicos de fácil asimilación, sobre los hechos que acontecieron durante aquellas fechas. De modo que mientras que desde el ámbito académico se apunta que la represión de posguerra en el País Vasco tuvo un carácter menos lesivo en comparación con otras provincias de similares características, la narrativa memorística o militante sostiene justamente lo contrario; esto es, que la represión de los sublevados, tildada de genocida, fue encaminada al aniquilamiento del "pueblo vasco». El último apartado ahonda en esta cuestión presentando los números y los factores que condicionaron el ejercicio de la represión de posguerra permitiendo así, por un lado, desechar definitivamente las teorías «exterministas», así como matizar las tesis del «oasis» defendidas por ciertos sectores de la academia.

\title{
Palabras clave
}

Franquismo; posguerra; represión; País Vasco.

\begin{abstract}
This article aims to analyze the debates generated about postwar Francoist repression in the Basque Country. First, the article notes that the undeniable advance of academic historiography in relation to Spanish civil war and postwar has not prevented a strong social implementation of some kind of thesis, characterized by being divorced from academy, based on clear ideological view and also on easy assimilation clichés, on events that took place during that time. So while from academia is indicated that repression in Basque Country did not reach virulence level deployed in the most of the rest of provinces, militant narratives presents Francoist repression as a secular Spanish genocidal project aimed at annihilating "basque nation". The last part delves into the matter showing the numbers and factors that conditioned postwar repression in the Basque Country. The article concludes discarding definitely "extermination" theories but also questioning "oasis" thesis advocated by some academic authors.
\end{abstract}

\section{Keywords}

Francoism; postwar; repression; Basque Country. 
I. INTRODUCCIÓN. II. ¿̇EXTERMINIO? III. ¿̇OASIS? IV. LA REPRESIÓN DE POSGUERRA EN EL PAÍS VASCO. V. NI EXTERMINIO, NI OASIS. BIBLIOGRAFía.

\section{INTRODUCCIÓN}

La última Guerra Civil española en el País Vasco, 1936-1937, es, sin lugar a dudas, el acontecimiento del pasado que mayor interés ha despertado en la sociedad vasca contemporánea. La formidable relevancia que este periodo histórico ha adquirido se constata con tan solo observar la gran cantidad de investigaciones y producciones de todo tipo (orales, audiovisuales, artísticas...) que se han ido presentando a lo largo de estos últimos treinta años. De hecho, no sería extraño que ante semejante oleada de trabajos sobre la Guerra Civil se considerara que nada o poco queda por conocer sobre este complejo y traumático periodo histórico. Bien es cierto que los avances de la historiografía en este terreno han sido evidentes y que en consecuencia la ciudadanía dispone en la actualidad de un sólido y riguroso soporte documental sobre los hechos más trascendentales que acontecieron durante aquellas fechas ${ }^{2}$. Sin embargo, no deja de ser menos cierto que aún quedan relevantes aspectos que nos son desconocidos y necesitados de investigación, a la par que incógnitas por descubrir sobre los hechos que acontecieron durante el enfrentamiento militar y, en mayor medida, sobre lo acaecido tras la victoria de los sublevados en el País Vasco.

De acuerdo con lo expresado, por ejemplo, nada o poco sabemos sobre los miles de capturados progubernamentales que en edad militar fueron enrolados forzosamente en las filas sublevadas y enviados al frente al servicio de la «causa nacional»; o del «franquismo sociológico» ${ }^{3}$ que sostuvo al «nuevo Estado» en el País Vasco; o de las actitudes y comportamientos sociales de los derrotados,

2 En cuanto a la Guerra Civil destacaría el exhaustivo listado proporcionado por De La Granja y De Pablo (2009). Por lo que a la represión franquista desplegada en el País Vasco respecta, destaco las siguientes obras: Gómez Calvo (2014); Barruso (2005); Aizpuru (2007), y Zubiaga (2017). Y entre los pocos estudios referentes a las actitudes sociales acontecidas durante la inmediata posguerra en el País Vasco, estas otras: Calvo (1995) y Zubiaga (2016).

3 Molina y Pérez (2015): 20 [Introducción]. 
fuerzas políticas incluidas, tras la victoria militar de los golpistas; o de las culturas políticas de los partidos y sindicatos de la época; o de las consecuencias que la represión franquista ocasionó en Euskadi, pues desconocemos el alcance total de la represión; o qué decir de la escasa atención que se ha prestado a los efectos de la represión ejercida por el bando republicano en el País Vasco, etc.

En realidad, a estas alturas la existencia de semejantes lagunas historiográficas resulta un tanto llamativa teniendo en cuenta el elevado volumen de producciones que han tratado la temática de la Guerra Civil y la posguerra en Euskadi. En este sentido, no me cabe duda que detrás de ciertos vacíos historiográficos no existe otra causa que la ausencia de pruebas de calidad que documenten lo ocurrido. No obstante, al mismo tiempo parece evidente que no todas las ausencias historiográficas han sido consecuencia de la imposibilidad de localizar fondos documentales sobre la cuestión. En este sentido, parece razonable considerar que la elección del objeto de estudio de una buena parte de las investigaciones de raíz histórica suele estar condicionado por las preocupaciones del presente. Así se entiende, por ejemplo, que tras cuarenta años de dictadura la inmensa mayoría de las iniciativas investigadoras durante los años ochenta y noventa fueran encaminadas a descubrir todo aquello que el régimen dictatorial había impedido conocer y que, por tanto, buena parte de los estudios fueran dirigidos a desmontar los mitos que el franquismo había elaborado: la inevitabilidad y la licitud del golpe militar, la intrínseca maldad de las fuerzas del bando progubernamental (los «anti-España») o los números de la represión. Ahora, en cambio, pasado ya ese escenario, habría que preguntarse las razones por las cuales siguen aún sin investigarse ciertos pasajes, paradójicamente los más incómodos, de la guerra y la posguerra en Euskadí.

Afortunadamente, la situación historiográfica actual en el País Vasco dista mucho de la entonces, los ochenta y noventa, pues los mitos franquistas, pese a la existencia aún de hagiógrafos del franquismo, sin ninguna relevancia académica, han sido ampliamente superados y desmontados. Sin embargo, sin apenas

4 Santiago de Pablo, por ejemplo, refiriéndose a la tendencia de ciertos sectores políticos y sociales de abultar las cifras de la represión franquista en el País Vasco, apuntaba lo siguiente: «Las cifras aportadas [por la Comisión interdepartamental del Gobierno Vasco de 2002] parecen ser consecuencia de un deseo de querer superar el número de víctimas de otras regiones. Inicialmente se habló de 5500 fusilados en las tres provincias, para poco después, quizá ante la imposibilidad de sostener cifra tan abultada, rebajarla a 3100, que parece también exagerada a la luz de las escasas investigaciones existentes, lo que quizá no es casual, puesto que tal vez no interese comparar las cifras reales de la represión en Euskadi con las mucho más altas de Castilla o Extremadura» (De Pablo, 2003: 116). 
tiempo para la complacencia, nuevos mitos y leyendas acerca de la Guerra Civil y la represión franquista han logrado penetrar en el imaginario de buena parte de la sociedad vasca o bien han sido reformulados al compás de las necesidades del presente. Este fenómeno no sería posible sin la participación de una corriente de «investigadores» que presentándose como historiadores ha elaborado relatos conscientemente edulcorados, cual arma política, al servicio exclusivo de los intereses de una identidad y una corriente ideológica determinada. De forma que esta nueva tendencia militante, en sintonía con los intereses de un sector de la ciudadanía, ha logrado institucionalizar en la esfera social y política un tipo de relato, de escasa rigurosidad analítica, repleto de tópicos de fácil asimilación sobre la historia de los vascos en clave nacional e identitaria.

De hecho, la gran mayoría de los debates que se plantean en el País Vasco en torno a la Guerra Civil y la represión ofrecen un mismo panorama: por un lado, las tesis académicas basadas en investigaciones sujetas a una metodología homologada, siempre sometidas a revisión y debate, y por otro, interpretaciones del pasado con fuerte carga militante adscritas a corrientes memorísticas. Como cabría suponer, la rigurosidad y la solvencia de los trabajos académicos en el terreno puramente analítico, lógicamente, es mayor. Sin embargo, por contradictorio que resulte, no es menos cierto, que la proyección y penetración social de los relatos militantes es alarmantemente superior.

\section{II. ¿EXTERMINIO?}

La adopción de un estilo narrativo que persigue enjuiciar el pasado desde un prisma interpretativo "presentista» fuertemente ideologizado es la principal seña de identidad de este tipo de publicaciones. Por regla general,

5 Dicho lo cual, quede bien entendido que las representaciones construidas del pasado basadas en simplificaciones o maniqueísmos no se circunscriben exclusivamente a una temática, ni tampoco a un determinado espacio geográfico. En el ámbito de la Guerra Civil y la represión hay un buen ramillete de puntos sobre los que se mantiene una intensa controversia historiográfica; algunos de ellos son, por ejemplo, las conocidas teorías blanqueadoras de la sublevación militar y de la dictadura de los peyorativamente denominados «revisionistas»; algunas de las posiciones defendidas en torno a la ley de la «memoria histórica», que presentan como defensores del "pueblo» y la democracia a la totalidad de los oponentes al golpe de Estado; las polémicas hagiografías-biografías publicadas en el Diccionario Biográfico Español editado por la Real Academia de la Historia; las interpretaciones descontextualizadas que presentan la guerra cual locura colectiva de responsabilidades equitativamente compartidas, etc. 
la interpretación emocionante y justiciera de esta «historia» ${ }^{6}$ suele ir acompañada de una utilización maniquea de la terminología y de una ausencia absoluta de diálogo crítico con las fuentes consultadas. Cabe subrayar que este fenómeno «literario» no se limita a los hechos acaecidos durante la Guerra Civil y el franquismo, pues, como bien apunta Antonio Rivera, «la historia militante, la historia con voluntad constructiva de presente, tiene una abundante tradición en el País Vasco»?

Habitualmente, este tipo de publicaciones de signo militante apuesta por un tipo de interpretación que en última instancia presenta la Guerra Civil en el País Vasco como una manifestación histórica más del irresoluble enfrentamiento secular entre el País Vasco y España ${ }^{8}$. A tenor de esta línea interpretativa, la represión y la dictadura franquista vendrían a demostrar, una vez más, la existencia de un proyecto secular genocida español encaminado al aniquilamiento del "pueblo vasco». Este tipo de obras suele optar también por el empleo sistemático de conceptos tales como genocidio y exterminio para sustantivar las acciones represivas desplegadas por los sublevados en el País Vasco. Sin embargo, la elección de este tipo de terminología no es producto de un análisis ponderado del valor terminológico de los conceptos, sino que su utilización persigue tan solo otorgar un carácter enfático al ejercicio de la represión franquista en el País Vasco que otorgue, normalmente a través de un epígrafe impactante, mayor gravedad e impacto a los hechos que se presentan?.

Al hilo de este punto, existe un cierto consenso entre la comunidad académica que esta particular concepción de la Guerra Civil y la represión tiene su origen en la lectura que un amplio sector del nacionalismo vasco confesional realizó tras la victoria militar de los sublevados. El golpe de Estado, la guerra y la represión fueron concebidas como una agresión más del Estado español hacia "Euzkadi» puesto que «en el fondo — tal y como sostenía la prensa nacionalista en febrero de 1937- nuestros enemigos de hoy no son sino

6 Esta particular narrativa tiende a confundir, valiéndonos en este caso de los conceptos que nos brindan tanto el inglés como el euskera, la History/Historia (disciplina que estudia en profundidad unos acontecimientos del pasado con arreglo a un método) con la Story/Istorioa (una sucesión de cuentos, relatos o anécdotas ficticias o reales sin pretensión científica alguna).

7 Rivera (2004): 43.

8 Además, también en esta cuestión se sigue el modelo de Irlanda en el sentido de que el mito fundacional del Estado irlandés es la lucha ancestral de sus habitantes frente a los ingleses. Véase, Rieff (2016): 25 y ss.

9 Egaña (2011a) y (2011b) e Irujo (2015). 
nuestros enemigos de siempre» ${ }^{10}$. Este relato que presentaba la guerra como un irresoluble enfrentamiento secular entre el País Vasco y España, siguió vigente en un sector del nacionalismo vasco tras la victoria militar franquista. No es casual que años después, en la década de los sesenta, un grupo de jóvenes vascos fundamentara su decisión de combatir militarmente al régimen franquista, entre otros factores, tal y como sostiene uno de sus antiguos miembros, en "una visión agónica de un pueblo vasco [oprimido] por invasores desde tiempos inmemorables [...] heredada del $\mathrm{PNV}{ }^{11}$. Este relato acompañado de la mitificación de los gudaris fue el que posibilitó que los miembros de ETA fueran presentados como los nuevos gudaris o salvadores de la patria vasca ${ }^{12}$.

Vemos, pues, cómo este tipo de narrativas, mayormente ligadas a corrientes memorísticas, tiende a elaborar relatos cargados de emoción, victimismo y moralismo con la misión, utilizando las palabras de Santos Juliá, de "pretender llenar de sentido el presente trayendo a la conciencia un hecho del pasado ${ }^{13}$. En este sentido, por ejemplo, es especialmente significativo el tratamiento, sobredimensionado a la par que heroico o doliente, según el caso, que reciben ciertos pasajes de la guerra. De esta forma, mientras se alude reiteradamente desde el ámbito social y político, mayormente desde un prisma "ahistórico» a un mismo lote encorsetado de acontecimientos (bombardeo de Gernika, la lucha militar de los gudaris, la actividad del Gobierno Vasco durante la guerra y el exilio, el enfrentamiento naval del Matxitxako o el exilio infantil), se mantienen relegados u ocultos aspectos esenciales de la guerra. Entre esos casos de «olvido» se pueden citar a la omisión de los combatientes no nacionalistas que defendieron la legalidad republicana en Euskadi, o los miles de voluntarios vascos y navarros que defendieron con las armas la sublevación, así como la actitud titubeante de ciertos dirigentes y sectores jeltzales ante la sublevación militar, las rendiciones de las unidades nacionalistas acaecidas en Bilbao y en Santoña, las distintas dimensiones «social, religiosa, de clase, etc.» del enfrentamiento bélico, la respuesta de la ciudadanía vasca ante el asentamiento del régimen franquista, las abiertas tensiones y enfrentamientos surgidos entre las

10 De la Granja (1990): 238.

11 Uriarte (2013): 50; Molina y Pérez (2015), y Fernández y López (2012).

12 ETA, concretamente la corriente adscrita a la base lingüística de Txillardegi, de los años setenta, fue uno de los primeros agentes que interiorizó el relato del genocidio cultural de los vascos que venía alimentándose desde algunos sectores del nacionalismo vasco confesional tras la derrota en la Guerra Civil (Fernández y López, 2012: 53; Núñez, 2007: 599, y Fernández, 2014: 260-261).

13 Juliá: «Memorias en lugar de memoria», El País, 2-07-2006. 
distintas formaciones políticas que formaban el bando progubernamental, los sucesivos intentos de paz separada acontecidos durante los primeros años de la Guerra Civil o, como último ejemplo, las implicaciones y consecuencias de los asaltos a las cárceles bilbaínas, etc.

Como no podía ser de otra forma, esta especie de relato «oficial» de la guerra y sus consecuencias genera verdadera perplejidad y desazón en buena parte del ámbito de la historia académica, pues existen suficientes trabajos historiográficos capaces si no de aclarar todas las cuestiones, sí de ofrecer una mirada relativamente cabal y desprejuiciada de lo acontecido durante aquellos $a_{n}{ }^{14}{ }^{14}$. Parece evidente que la difusión de ciertos mantras es posible en buena medida debido al escaso interés que suscitan las investigaciones académicas en los ámbitos políticos y sociales. A este respecto, no cabe duda que una parte considerable de la responsabilidad del citado escenario recae en el carácter endogámico de buena parte de los debates historiográficos. En todo caso, sería injusto responsabilizar exclusivamente a los historiadores de la escasa trascendencia pública que logran sus trabajos. Existen factores importantes tales como el funcionamiento de los medios de comunicación masivos o las correlaciones políticas del momento, que condicionan severamente la difusión de las investigaciones históricas. Además, a nadie escapa que la historia, de naturaleza imprevisible, incomoda y desmitificadora, tiene un difícil encaje en una sociedad en la que, como diría Antonio Muñoz Molina, «el prejuicio [y el sectarismo] es mucho más natural que la vocación sincera del saber ${ }^{15}$.

Sin lugar a dudas, el protagonismo que ha adquirido el concepto de la «memoria» durante estos últimos años explica en buena medida la rápida institucionalización de los relatos «partisanos» y el enraizamiento de ciertos lugares comunes sobre la materia que aquí nos ocupa. En todo caso, es necesario subrayar, con el objeto de evitar equívocos, que la memoria no tiene por qué ser obligatoriamente falsa sino que, en comparación con la historia, su elaboración y objetivos descansan sobre parámetros totalmente distintos. Así pues, mientras que la memoria se elabora desde la subjetividad y es, por tanto, sesgada y autojustificadora, por lo que tiende a elaborar relatos acomodaticios y atractivos al grupo al que se destina ${ }^{16}$, la misión de la historia pasa por presentar unos resultados con arreglo a un método de investigación, sujetos a un permanente debate sin complejos y en constante revisión. La memoria, además, de naturaleza dúctil y acomodaticia, es en contraposición con la historia, una herramienta de

A este respecto, véase el análisis de Molina (2014): 296-319.

15 Muñoz Molina (2013): 103.

16 Como señalaba Judt (2006): 1182, «la memoria es intrínsecamente polémica y sesgada. Además es una mala consejera en lo que al pasado se refiere». 
enorme utilidad para el fortalecimiento del sentido de pertenencia y de la identidad social, pues "coadyuvan a preservar las fronteras identitarias y a mantenerlas relativamente estables frente a otros grupos sociales ${ }^{17}$. De aquí se desprende, entonces, la buena acogida que los memoriales y los testimonios de las víctimas despiertan en la práctica totalidad de la clase política. No en vano, la memoria, aunque también la mala historia, de nuevo en contraposición con la historia, reúne todos los condicionantes para ofrecer una rentabilidad política inmediata.

\section{III. ¿OASIS?}

En este orden de cosas, numerosos estudiosos de la represión franquista han denunciado la manifiesta parcialidad, tendenciosidad e incluso la falsedad de los datos que manejan ciertos estudios sobre el alcance de la represión el País Vasco ${ }^{18}$. El investigador Francisco Espinosa, por ejemplo, apuntaba que "para una comunidad como Euskadi, que lleva ya décadas alimentando el victimismo, no resulta fácil asumir que, frente a lo que se les ha contado siempre, la represión franquista allí fue de las menos duras de España $»^{19}$. Las tesis de Espinosa adquieren, si cabe, mayor contundencia al observar que, inexplicablemente, el Gobierno Vasco continúa dando por válidas cifras y listados de ejecutados plagados de errores ${ }^{20}$. En este sentido, a ningún

17 Casquete (2009): 41-43.

18 Espinosa (2009): 58-76; Pérez (2013): 61-62; Castells y Molina (2013): 222-223; De Pablo et al. (2013): 115-116 y 140; Gómez Calvo (2014): 141; Casquete et al. (2012): 450, y De Pablo en «La vieja memoria de 1936», El Correo Español, 8-2-2014. En el año 2000 varios historiadores de la UPV-EHU denunciaron por plagio la enciclopédica obra de historia coordinada por Egaña y titulada 1936. Guerra Civil en Euskal Herria/ 1936. Gerra Zibila Euskal Herrian. Los denunciantes aseguraban que «el libro [era] en determinadas partes de algunos volúmenes, un verdadero plagio, copiándose párrafos enteros sin apenas cambios respecto a los trabajos originales y sin citar las fuentes de información». Además señalaban que «todo este trabajo de collage (al que se han añadido, y es de justicia aclararlo, algunos datos nuevos de carácter local, recabados suponemos que en archivos municipales o en fuentes orales) ha[bía] dado como resultado una obra con numerosos errores y contradicciones, que no aporta[ba] prácticamente nada al conocimiento que la historiografía profesional — con sus lagunas y limitaciones - tenía ya de la Guerra Civil en Euskadi» (De Pablo, Barruso, Rivera y Ugarte, disponible en: http://www.h-debate.com/listahad/19-01-00.htm).

19 Espinosa (2010): 50.

20 Gobierno Vasco, Plan de Convivencia 2013-2016, p. 10. El Diario Vasco, 11 de diciembre de 2015, disponible en: http://www.jusap.ejgv.euskadi.eus/r47-contmh2/ 
profesional de la historia le sorprende que los trabajos firmados por Iñaki Egaña Sevilla, máximo exponente de la literatura «pseudohistórica» en Euskadi, se decanten por un relato emocionante y falseado del "pueblo" vasco y que para ello no tenga reparos en plagiar textos ajenos, infringiendo la máxima de la honestidad intelectual, o en abultar los listados de ejecutados con el afán de obtener un relato a la altura las expectativas nacionales de Euskal Herria. Sin embargo, el asunto adquiere mayor gravedad cuando es el Gobierno Vasco quien asume acríticamente estas cifras e incluso el relato cuando existen suficientes pruebas para su refutación ${ }^{21}$.

De un tiempo a esta parte, en contraposición con los relatos memorísticos y militantes citados, un buen número de trabajos provenientes del ámbito académico han ido presentando líneas argumentativas que chocan frontalmente con esa imagen de un País Vasco especialmente golpeado y castigado por el «nuevo Estado» durante la posguerra ${ }^{22}$. A tenor de esta corriente de reflexiones, la represión franquista en el País Vasco no alcanzó las cotas de virulencia y ferocidad vistas en otros territorios de España. De hecho, si nos atenemos a los listados de ejecutados que se manejan en la actualidad, el número porcentual de ejecutados en el País Vasco en relación con el número de habitantes sería de los más bajos de España $(0,16 \%)$, solamente superado por Cataluña $(0,12 \%)^{23}$. En líneas generales, el carácter menos lesivo de la represión en Euskadi se suele atribuir mayormente a las gestiones mediadoras de la Iglesia y a la cultura católica común de buena parte de los vencidos (principalmente los combatientes adscritos al Partido Nacionalista) con los sublevados.

es/contenidos/informacion/listado_personas_desaparecidas/es_memoria/a_listado_personas_desaparecidas.html. A poco que se ponga algo de atención e interés en el listado de muertos que presenta la página del Gobierno Vasco, se pueden entrever fácilmente errores tales como la doble contabilidad, la consignación como ejecutados de causas conmutadas o la contabilidad de personas fallecidas por consecuencias ajenas a la represión franquista. Asimismo, todos los ejecutados en Bizkaia son contabilizados como naturales o residentes vascos. Nada más lejos de la realidad. Numerosas personas no vascas fueron ejecutadas en Bizkaia. Una expresión de esta situación son los procesados por consejos de guerra de Cantabria que fueron trasladados a las cárceles vizcaínas, siendo muchos ellos posteriormente ejecutados en la villa.

21 Ver Gómez Calvo (2014): 47-51; Ruiz Soroa: «Los muertos que perdieron su identidad», El Correo Español, 20-4-2014, y Zubiaga (2017).

22 Fraser (2001) [1979]: 572; Garmendia y González (1993): 191; Jackson (2005) [1965]: 336; Espinosa (2010): 50; Preston (2011): 577; Gil (2010): 290, y Rivera y Gómez (2015): 50.

23 Datos elaborados en función de los datos proporcionados por Vega (2011): 336. 
Asimismo, por curioso que parezca, distintas personalidades afines a los sublevados manifestaron durante la posguerra opiniones similares a las arriba descritas, mayormente referidas al caso de Bizkaia $^{24}$, ya fuera en ámbitos públicos o privados. Así de contundente se mostraba, por ejemplo, el periodista Francisco Cossio en 1937 en su crónica de la «guerra de salvación» sobre la población vencida de la villa bilbaína: «Si uno de estos hombres viniese conmigo esta noche y yo pudiera tocar en su corazón... Mira, le diría, nosotros hemos podido imponer la ley del vencedor, y os tratamos como hermanos; en Castilla, en Aragón, en Andalucía, en Navarra... hemos sido mucho más duros con los disidentes y rebeldes que hoy lo somos con vosotros ${ }^{25}$.

Una idea similar apuntaba el pensador falangista Ernesto Giménez Caballero en unas declaraciones publicadas en el diario donostiarra La Voz de España de 1937: «Las columnas rescatadoras que Dios guía no tenían por qué actuar [en Bizkaia] con el ímpetu justiciero y purificador que en Badajoz y en Málaga $»^{26}$.

En la misma línea se ubican los textos escritos por el periodista Ruiz de Albéniz, publicados en 1942 bajo el seudónimo el Tebib Arrumi, en los que narraba la sorpresa de los corresponsales extranjeros al constatar que las tropas sublevadas no actuaban de forma vengativa con «los vizcaitarras que no [habían] querido huir de Bilbao ${ }^{27}$. Ahora bien, toda manifestación pública, más aún en un contexto de posguerra donde la legitimidad de los vencedores estaba en entredicho, ha de ser puesta en cuarentena, pues resulta realmente complicado conocer a ciencia cierta si las manifestaciones aquí recogidas descansaban sobre análisis y reflexiones sinceras o, por el contrario, estaban teledirigidas y no aspiraban más que a publicitar las «bondades» del «nuevo régimen» en Bizkaia.

No obstante, la privacidad y el carácter oficial de las memorias de Felipe Acedo Colunga, fiscal jefe del «ejército de ocupación», constatan que las tesis acerca de la menor dureza represiva implementada por las tropas sublevadas, al menos en Bizkaia, era compartida también por algunos altos cargos militares franquistas. Las memorias del fiscal, rescatadas por Frascisco Espinosa del Archivo Militar Territorial Segundo de Sevilla, denunciaban que la legislación

\footnotetext{
24 El libro publicado en 1940 por el Centro de Información Católica Internacional, atribuido al jesuita Constantino Bayle y dedicado a la cuestión de la clerecía vasca, declaraba que "con la victoria total en el Norte la benignidad fue norma». Centro de Información Católica Internacional (1940): 222.

25 Cossio (1937): 169.

26 VV. AA. (1998): 85-86.

27 Tebib Arrumi (1942): 259.
} 
militar de posguerra se había impuesto con menor severidad en Bizkaia debido tanto a «razones políticas de campaña», así como a la falta de colaboración de los ciudadanos vizcaínos en el encausamiento de sus convecinos ${ }^{28}$.

\section{LA REPRESIÓN DE POSGUERRA EN EL PAÍS VASCO}

Llegados a este punto y tras haber mostrado las tesis principales que giran en torno al ejercicio de la represión franquista en el País Vasco, es momento de contrastar dichas teorías con los últimos avances publicados sobre la cuestión. Dicho de otro modo, ¿las últimas investigaciones corroboran las tesis acerca de la menor intensidad represiva ejercida por los sublevados en el País Vasco?

A este respecto, los números de ejecutados que disponemos en la actualidad, aún sin clarificar en su totalidad, confirman que la intensidad de la represión en las provincias vascas fue porcentualmente de las más bajas de España. Sin embargo, en este punto hay que añadir de inmediato que la represión de los sublevados no se limitó a la muerte, pues la implantación del «nuevo Estado» franquista se caracterizó por el empleo de múltiples medidas e instrumentos coercitivos. La reclusión, las depuraciones laborales, las sanciones económicas, el destierro o el exilio son, por ejemplo, buen exponente de las otras formas que adoptó la represión. De todas formas, a nadie escapa que la eliminación física del adversario es la máxima representación, la más atroz, del ejercicio del terror y que, por lo tanto, sus consecuencias e impacto no son equiparables a ningún otro método coactivo.

De igual forma, pese a que los planes de la Junta Militar radicada en Burgos eran de aplicación general y sus consecuencias dramáticas tuvieron un largo alcance en todos los territorios del país, la singularidad territorial de la represión es a estas alturas un hecho contrastado. La represión no se ejecutó, ni en forma ni en intensidad, de la misma manera en todas las regiones. Los numerosos estudios territoriales que disponemos en la actualidad nos permiten desechar las teorías generalistas que tratan de establecer un mismo patrón represivo para todo el Estado. El caso del País Vasco no fue una excepción. Como es bien sabido, la intensidad y los métodos represivos franquistas fueron variando en función del tiempo y el espacio ${ }^{29}$. Así, por ejemplo, mientras

\footnotetext{
Espinosa (1999): 34-39.
}

29 Por regla general, buena parte de la historiografía especializada en la cuestión diferencia tres periodos represivos durante el proceso inicial de consolidación del nuevo Estado rebelde: la primera fase, de julio 1936 a inicios de 1937, corresponde a la 
que las provincias de Álava y Gipuzkoa sucumbieron rápidamente al control sublevado, momento en el cual la represión era canalizada eminentemente a través de una violencia no reglamentada, Bizkaia, conquistada en junio de 1937, caía en un periodo donde el ejercicio de la represión había sido en buena medida sustituido por un tipo de represión «legal», también denominada «terror frío», canalizada a través de los consejos militares y del sistema penitenciario. Con todo, hay que apuntar que las fases represivas tienen un carácter orientativo, pues las mismas indican únicamente la preeminencia de ciertas pautas represivas sobre otras y, por tanto, no niegan la coexistencia de distintos tipos represivos durante un mismo espacio-tiempo.

Esto es lo que sucede, por ejemplo, con los casos de Álava y Gipuzkoa. El ejercicio de la represión en estas provincias no alcanzó el grado de virulencia y ferocidad desplegadas en otros territorios conquistados en el mismo periodo tales como el suroeste de Andalucía, Navarra, La Rioja o Zaragoza. La ausencia de oposición al golpe posibilitó en gran parte de los territorios conquistados el ejercicio unilateral de una violencia ejemplarizante que pretendía, a través del terror, la rápida consecución de los resortes del poder ${ }^{30}$. Los números de la represión de este periodo escenifican a la perfección el alcance de dicha violencia. No en vano, el $70 \%$ del total de las víctimas de la represión durante la guerra y la posguerra en España se concentraron en los escasos meses que siguieron al golpe de Estado ${ }^{31}$. Tal diversidad no hace sino asentar la complejidad del asunto, y obliga a puntualizar que no todos los territorios bajo control sublevado desde el inicio fueron objeto de un tipo de represión caracterizado por esa violencia extrema y masiva sin contemplaciones hacia el adversario.

Por lo que al caso alavés respecta, el ejercicio de la represión durante la posguerra dejó un balance de 160 víctimas mortales producto de los asesinatos «extrajudiciales» y 33 consecuencia de sentencias en consejos de guerra ${ }^{32}$. Aunque la historiografía aún no ha dilucidado el número total de ejecutados acontecidos en Gipuzkoa, los datos aproximativos que disponemos apuntan que los sublevados ejecutaron, mayormente por vías «judiciales», entre 485 y 500 personas $^{33}$. Así, pues, pese a la gravedad de los hechos, la magnitud de la

preeminencia de la represión extrajudicial o «terror caliente»; la segunda, de diciembre 1937 a 1941, se caracteriza por la consolidación de un tipo de represión «institucional», y, por último, la tercera etapa, 1941-1945, responde a una cada vez mayor depuración de los mecanismos de control social.

30 Gil (2004): 126.

31 Gómez y Marco (2011): 66.

32 Gómez Calvo (2014): 339-345.

33 Barruso (2005): 121. 
represión en Álava y Gipuzkoa no fue equiparable con lo acontecido en la mayor parte de las provincias conquistadas tras los primeros meses del levantamiento militar. El balance represivo de los sublevados en Bizkaia parece ofrecer un resultado similar. A falta de conocer el número total de ejecutados en la provincia vizcaína, los estudios aproximativos estiman que el número de ejecutados fue ostensiblemente menor que las cifras manejadas hasta la fecha ${ }^{34}$. Por lo tanto, a tenor de de la información que disponemos, podemos dar por válidas las tesis que apuntaban que la represión de posguerra en el País Vasco fue bastante más «blanca» que en otras zonas de España ${ }^{35}$.

Pero, cabe preguntarse, ¿qué factores y variables condicionaron el ejercicio de la represión en el País Vasco? ¿A qué se debió este hecho diferencial de la represión? ¿Fue Euskadi, en realidad, un oasis de la represión franquista?

Como ya he apuntado, no hay un único factor explicativo aplicable al caso vasco. Los diversos estudios constatan que la represión en cada provincia estuvo sujeta a unos ritmos, factores y variantes particulares. Aún así, no se puede obviar que las tres provincias comparten también cuestiones comunes de gran relevancia. La existencia de un partido como el PNV, católico y tradicional, en el bando progubernamental, por ejemplo, es una particularidad exclusiva del País Vasco. Como veremos, la catolicidad del PNV, adscrito al bando vencido, no fue un asunto baladí. La religión desempeñó un papel vital tanto en la guerra como en la posterior represión. No en vano, los mandos sublevados y la jerarquía eclesiástica española presentaban la Guerra Civil española como un enfrentamiento religioso entre la "civilización cristiana» y los «sin Dios» ${ }^{36}$.

En el caso de Álava, por ejemplo, es interesante destacar que la provincia durante el periodo de la República no fue escenario de graves conflictos políticos y sociales. La distribución de la propiedad de la tierra entre pequeños propietarios agrícolas favoreció que no estallaran las tensiones que habían surgido en buena parte del resto de las zonas agrícolas de España. Asimismo, el escaso desarrollo económico de la provincia no fue sinónimo, como venía siendo habitual, de pobreza extrema, analfabetismo generalizado (tres veces menor que la media nacional), enfrentamientos violentos de clase o desarraigo identitario $^{37}$. Lo que dominaba en esta provincia era una suerte de «vitorianismo» o

34 Zubiaga (2017). Diversos estudios, Egaña (1998-1999): 183-188; Vega (2011): 337, y Prada (2010): 438, afirman que la represión franquista en Bizkaia segó la vida a un número aproximado de 900 personas. El Instituto Valentín de Foronda, adscrito a la Universidad del País Vasco, dilucidará esta cuestión en un próximo estudio.

35 Garmendia y González (1993): 191

36 De la Granja (1987): 78; Rodrigo (2008): 109 y (2003): 60, y Juliá (1999): 20.

37 Gómez Calvo (2014): 66-67. 
"alavesismo», caracterizado por una especie de compromiso colectivo con el territorio y sus gentes, una mentalidad socialmente inclusiva, que vendría a mitigar en el plano sentimental las diferencias internas, actuando como un factor cohesivo, que tuvo el efecto de crear un clima contrario a aplicar una dura represión.

Asimismo, la sociedad de la «victoria» en Álava no alentó ni protegió la práctica inmisericorde de la persecución del convecino. De hecho, resulta llamativa, por insólita, la editorial publicada por el diario Pensamiento Alavés en septiembre de 1936 reclamando "justicia rígida [e] inexorable, pero justicia» para «los enemigos de España» en un momento en el cual los militares exhortaban el ejercicio de una violencia sin contemplaciones hacia el adversario ${ }^{38}$. De todas formas, estos velados llamamientos a la calma no evitaron los más de 150 crímenes en la región, planificados y dirigidos por las nuevas autoridades, perpetrados mayormente por cuadrillas de requetés y falangistas.

Junto con todo lo anterior, habría que considerar también el papel de los carlistas alaveses. El colectivo tradicionalista, corriente política mayoritaria de los sublevados en la provincia, consideraba que buena parte de los nacionalistas vascos eran perfectamente «recuperables» para los intereses del «nuevo Estado». En esta dirección, ciertos sectores de la sociedad alavesa de la «victoria» eran conscientes que la titubeante actitud de los mandos y simpatizantes del PNV ante el golpe militar en Álava ${ }^{39}$ y los principios del partido (familia, religión, tradición y orden) posibilitaban el tránsito y la conversión de una buena parte de los nacionalistas vascos al nuevo orden ${ }^{40}$. En realidad, tal y como apuntaba Ruiz de Apodaca, líder de una patrulla de requetés responsable de parte de los asesinatos acontecidos en Álava, solo había que distinguir entre dos tipos de nacionalistas vascos: los arrepentidos y los que no lo esta$\operatorname{ban}^{41}$. Así pues, la cultura compartida de ambas formaciones en torno a la política y el "comunitarismo» de la región fue uno de los factores decisivos que mitigó el impacto de la represión en la provincia, al menos por lo que a los nacionalistas confesionales vascos respecta.

Por otro lado, aunque los estudios publicados sobre Gipuzkoa hasta la fecha no dilucidan por completo el asunto que aquí nos ocupa, proporcionan sugerente información que podría explicar en parte los números de la represión en la provincia. En primer lugar, todo apunta a que el posicionamiento de los carlistas en Gipuzkoa en relación con los nacionalistas vascos no fue tan

\footnotetext{
Ibid., 85.

De Pablo (1990): 30-33.

Gómez Calvo (2014): 119 y 119.

Ibid., 116.
} 
integradora como en Álava. La alianza del PNV con las fuerzas izquierdistas en defensa del orden constitucional en las provincias de Gipuzkoa y Bizkaia generó un profundo malestar en las filas carlistas. Los tradicionalistas consideraban que semejante actitud no solo había impedido y retrasado la victoria militar de los sublevados en dichas provincias, sino que había enfrentado innecesariamente a miles de católicos. Así pues, no faltaron voces en el seno del carlismo que exigieron una represión sin cuartel a los «traidores» nacionalistas vascos por haberse aliado con el gobierno del Frente Popular y posicionado contra el «alzamiento» de las «fuerzas del orden» ${ }^{42}$. De hecho, la represión en Gipuzkoa fue dirigida inicialmente a perseguir prioritariamente a los elementos que formaban el sustrato ideológico del nacionalismo vasco en la provincia ${ }^{43}$. El alto número de condenados nacionalistas durante los dos primeros años de posguerra es un fiel indicativo de la inquina inicial desatada hacia los sectores nacionalistas en Gipuzkoa. La condición de religiosos, por ejemplo, tampoco fue impedimento para acabar con la vida de 13 clérigos acusados de simpatizar con el nacionalismo vasco durante la primera fase de la conquista militar de Gipuzkoa ${ }^{44}$.

El revuelo y escándalo internacional que generaron el fusilamiento de los religiosos, sobre todo en el Vaticano, motivaron un cambio drástico en la estrategia punitiva de los sublevados ${ }^{45}$. El propio cardenal Gomá, primado de España y representante "confidencial y oficioso» del Vaticano ante el Gobierno de Franco, comunicaba en un informe enviado al Vaticano el 8 de noviembre de 1936 que el general Franco desconocía y reprobaba el fusilamiento de los sacerdotes y que el asunto "quedaba cortado inmediatamente» ${ }^{46}$. Sea como fuere, los fusilamientos previstos de clérigos vascos fueron suspendidos. Consecuentemente, ningún clérigo disidente capturado durante la conquista de Bizkaia y Cantabria fue ejecutado tras sentencia en consejo de guerra ${ }^{47}$. No obstante, este hecho no evitó que numerosos religiosos fueran encarcelados y sometidos a consejos de guerra.

42 Jackson (2005) [1965]: 328.

43 Barruso (2005): 146.

44 De Pablo et al. (2013): 348-349. En un estudio anterior del propio autor se manejaban cifras mayores: «16 sacerdotes y religiosos fueron fusilados por las tropas franquistas entre septiembre y noviembre de 1936.» De Pablo et al. (2001): 24-25.

45 Sole y Villaroya (1999): 205.

46 Rodríguez (1981): 62.

47 Cabe señalar que el carmelita Román de San José fue ejecutado extrajudicialemente tras la ocupación de la localidad de Amorebieta (Bizkaia), en mayo de 1937. De Pablo et al. (2013): 348-349. 
El factor geográfico es otro de elementos que vendría a explicar los números de represión en la provincia. A este respecto, la situación geográfica de Gipuzkoa, limítrofe con Francia, habría posibilitado la huida de numerosas personas antes de la toma militar de la provincia ${ }^{48}$. En consecuencia, personas con destacados antecedentes políticos hostiles a los sublevados pudieron sortear así un más que probable castigo. Sea como fuere, pese a los valiosísimos aportes historiográficos de los profesores Barruso y Aizpuru, la radiografía de la represión en Gipuzkoa continúa a la espera de ser completada.

El caso de Bizkaia es también un buen exponente donde corroborar la singularidad territorial de la represión franquista. En primer lugar, como es bien sabido, la particular coyuntura de la guerra en el frente norte motivó que la mayoría de los combatientes vascos fueran capturados, incluso procesados, encarcelados y ajusticiados en la provincia de Cantabria. Esta circunstancia, por tanto, obliga a todo estudioso que pretenda abordar el caso vizcaíno en su profundidad, incluir en el análisis lo acontecido en sus vecinas Cantabria, en mayor medida, y Asturias.

Asimismo, el territorio vizcaíno, a diferencia de Álava y Gipuzkoa, fue conquistado en el momento que los métodos de violencia indiscriminada habían sido sustituidos gradualmente por el empleo sistemático del procedimiento sumarísimo de urgencia en los consejos de guerra ${ }^{49}$. Desde el 26 enero de 1937 el decreto franquista número 191 había establecido el procedimiento y la jurisdicción que seguir en todas las "plazas liberadas $»^{50}$. Dicho decreto no hacía más que extender las condiciones de otro anterior, el número 55, diseñado para la toma de Madrid, al resto de los territorios ocupados. El predominio del ejercicio de la represión «institucionalizada» en Bizkaia ofreció a los encausados mayores posibilidades de salvar la vida, si bien dentro de un régimen caracterizado por un funcionamiento netamente arbitrario y carente de criterios sancionadores definidos ${ }^{51}$.

48 Aizpuru (2007): 94.

49 Ruiz (2005): 171-191. Sin embargo, hay que advertir también que existen poderosas excepciones que cuestionan este planteamiento. Los números de la represión franquista desplegada en Málaga y Asturias, por ejemplo, indican que el predominio de los tribunales militares no implicó un descenso del número de ejecutados, pues las víctimas mortales por consejos de guerra rondaron las 7000 y 6000 respectivamente. Anderson (2014): 91.

50 BOE, 27 de enero de 1937.

51 Los tribunales militares sitos en Bilbao fallaron la condena capital en $9 \%$ las causas vistas. Cabe señalar que no todas que no todas las sentencias de muerte conllevaron la ejecución del procesado. Concretamente, el $50 \%$ aproximadamente de las penas 
El cambio de la estrategia punitiva de los sublevados, la progresiva implantación de una violencia reglamentada, respondía en gran parte al deseo de justificar el golpe y legitimar el nuevo orden militar ante la opinión pública internacional ${ }^{52}$. La mayor presión mediática internacional sobre España dificultaba, cada vez más, la ocultación o minimización de las consecuencias del ejercicio de una política represiva no regulada ante las diplomacias internacionales. Es por ello que el mensaje del bando franquista trató en todo momento de presentar al gobierno de Salamanca como único garante de la defensa del orden en España y de identificar toda acción luctuosa con la implantación del «terror rojo» republicano.

En cualquier caso, la incidencia de la burocratización de la represión no fue el único aspecto que aminoró el efecto de la represión en Bizkaia. Las últimas investigaciones desvelan que las labores diplomáticas desarrolladas por el Vaticano, la Italia fascista y personalidades políticas del Reino Unido, destinadas a suavizar el efecto de la represión sobre las bases y dirigentes del nacionalismo vasco confesional, lograron evitar el fusilamiento de numerosos combatientes vascos. Las presiones de estos agentes internacionales vendrían a revelar «las razones políticas de campaña», manifestadas por el fiscal jefe del ejército franquista, Felipe Acedo Colunga, anteriormente citadas, que implicaron un descenso de la intensidad represiva desplegada en Bizkaia.

La Santa Sede, por ejemplo, en opinión del Secretario de Estado del Vaticano, no deseaba «otra cosa sino que renazca la paz entre sus hijos»; en otras palabras, quería acabar cuanto antes con el enfrentamiento entre católicos en Bizkaia $^{53}$. Sin embargo, los sucesivos intentos promocionados con el objeto de acordar una paz separada entre los nacionalistas vascos y los militares sublevados no dieron resultado hasta agosto de 1937, momento en cual aconteció

capitales fueron finalmente conmutadas por la pena de 30 años de reclusión mayor (Zubiaga, 2017).

52 Al parecer esta política propagandística tuvo el efecto deseado en parte de la diplomacia internacional. Así fue al menos en el caso del Reino Unido. En febrero de 1939 el primer ministro británico, Neville Chamberlain, reconocía al Gobierno de Franco destacando, entre otras cosas, el buen funcionamiento de la «Administración de la justicia» en la España «nacional». Sin embargo, todo apunta que la Administración británica era plenamente consciente de la falta de garantías de la justicia franquista. El reconocimiento británico se debía, por tanto, a otro tipo de motivaciones, tales como la búsqueda del alejamiento de la España de Franco del temido eje Berlín-Roma. Como se puede apreciar, la condescendiente actitud británica respecto a la dictadura de Franco no fue más que el antecedente de su fatal política de apaciguamiento. Anderson (2014): 85 y 93.

53 Olazábal (2009), T.I: 2006. 
el denominado "pacto de Santoña». Ante la inminente caída de Bilbao y ante la imposibilidad de lograr un final acordado, a partir de abril de 1937 el Vaticano comenzó a encauzar sus esfuerzos a moderar las medidas que iban a tomarse contra los católicos vascos y especialmente contra los sacerdotes acusados de simpatizar con el nacionalismo vasco ${ }^{54}$.

Finalmente, el Vaticano aceptó el 27 de agosto de 1937 reconocer oficialmente al Gobierno de Franco tras un largo y duro proceso de negociación. El marqués de Aycinena fue recibido oficialmente por el cardenal secretario de Estado del Vaticano para la presentación de las cartas que lo acreditaban como encargado de negocios del Gobierno de Franco en la Santa Sede ${ }^{55}$. Tras la lectura de los informes podemos deducir que el Vaticano reconocía oficialmente al régimen franquista a cambio de obtener el compromiso que sus exigencias serían satisfechas, entre las que se encontraba la petición de una mayor benevolencia en el tratamiento hacia los católicos nacionalistas vascos. Una carta enviada desde el entorno nacionalista a Mateo Múgica, antiguo obispo de Vitoria instalado en Roma, en octubre de 1939 agradeciendo las gestiones realizadas «para obtener la salvación de un número muy considerable de prisioneros vascos condenados a muerte», confirma que, al menos, en cuanto al tratamiento de los rendidos vascos respecta, la entente Vaticano-Gobierno franquista dio resultados satisfactorios ${ }^{56}$.

Por el contrario, la intervención de la Italia fascista descansaba sobre motivaciones distintas. Tras el caótico desenlace del «pacto de Santoña», el ejército italiano solicitó en numerosas ocasiones clemencia hacia los rendidos vascos con el objeto de salvaguardar su imagen ante la opinión pública internacional. Mario Roatta, general de una división de la CTV (Corpo di Truppe Volontarie), fue una de las primeras personalidades del mando del ejército italiano que se entrevistó con Franco, el 8 de septiembre de 1937, con el fin de abordar la cuestión de los prisioneros vascos. Los mandos italianos entendían que los «vascos» se habían rendido cuando ya estaban aislados y que "desde el punto de vista jurídico material no [tenían] derecho a la aplicación de las condiciones en su momento pactadas». Sin embargo, «desde un punto de vista moral» juzgaba que se les debería conceder «las más importantes de las condiciones convenidas» a excepción «de los condenados o reos de delitos verdaderamente comunes».

54 Rodríguez (1981): 217-218.

55 Olazábal (2009), T. III: 186.

56 Archivo Histórico de Euskadi (en adelante, AHE), 1939-1939. Expediente tramitado por la Delegación de París para la consecución de conmutaciones de penas de muerte contra presos vascos, generado en base a cartas remitidas a diversas personalidades religiosas y políticas y listados de presos condenados a muerte. Legajo: 13. Número legajo: 11 . 
El general Franco contestó a la petición del militar italiano indicando que no estaba dispuesto a exonerar a la totalidad de los rendidos vascos, pues debía satisfacer también los deseos de venganza clamados por una buena parte de sus filas, si bien se comprometía a ejecutar a «un número relativamente exiguo de condenados a muerte». El resto de las penas capitales, «la mayoría» a

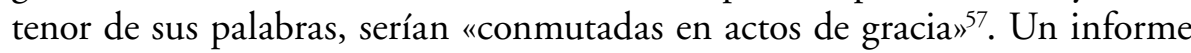
«altamente confidencial» del embajador italiano en Salamanca, enviado al conde Ciano, ministro de Asuntos Exteriores italiano, en noviembre de 1937, señalaba que los tribunales militares estaban empleando «en toda la medida posible» criterios de «indulgencia» en el juicio de los católicos vascos ${ }^{58}$. Los informes internos del máximo órgano del PNV apuntaban en la misma dirección. Los mandos nacionalistas vascos en el exilio reconocían que las gestiones italianas "ha[bían] salvado la vida a muchos de nuestros compatriotas»"

En el mismo sentido, el diputado laborista inglés George Lansbury intercedió también, oficialmente a título individual, por la suerte de los rendidos vascos a través de contactos con la embajada italiana en España. El propio ministro de Asuntos Exteriores italiano, el conde Ciano, consideraba que la intervención de Lansbury, «el más viejo de los parlamentarios británicos y uno de los más respetados [podría] indudablemente ayudar a la causa» de los suble$\operatorname{vados}^{60}$. Años después, el 31 de julio de 1939, informes del Gobierno Vasco en Londres manifestaban que las gestiones realizadas por el diputado inglés podrían haber beneficiado a buena parte de los rendidos vascos. Incluso una persona destacada del PNV en el exilio, Ángel Gondra, agradecía abiertamente en una carta enviada en agosto de 1937 al propio Lansbury su labor en la salvación de las vidas de presos vascos: «You will, perhaps, remember that you intervened on our behalf about a year ago, but you may not be aware that your intervention at that time was instrumental, in our behalf, in saving a number of men from execution ${ }^{61}$.

Olazábal (2009), T.III: 240.

58 Ibid.: 290-291.

59 AHE, 1939-1939. Correspondencia, fechada entre el 27 de julio y el 28 de septiembre de 1939, mantenida entre Antonio Gamarra, miembro del EBB del PNV con Ángel Gondra, sobre las gestiones realizadas por el diputado británico George Lansbury a petición de la Delegación del Gobierno de Euzkadi en Londres a fin de que influyera en las autoridades españolas e italianas para que cumplieran lo acordado en el Pacto de Santoña y ayudar de ese modo a los presos.

60 Olazábal (2009), T.III: 229-230.

61 AHE, 1939-1939. Correspondencia, fechada entre el 27 de julio y el 28 de septiembre de 1939, mantenida entre Antonio Gamarra, miembro del EBB del PNV, con 
Junto con todo ello, no podemos dejar de considerar el número de bajas mortales que acontecieron durante la defensa militar del último reducto republicano en el País Vasco. El balance de los combates acaecidos en Bizkaia desde el inicio de la ofensiva de Mola, 31 de marzo, hasta la caída de Bilbao, 19 de junio, fue estremecedor por lo que al número de muertos respecta. Se calcula que el ejército progubernamental sufrió entre 4500 y 5000 bajas mortales en los escasos dos meses y medio que duró la campaña militar franquista en el territorio vizcaíno ${ }^{62}$. Tal fue la crudeza del enfrentamiento en los frentes de guerra que solamente durante la ofensiva sobre la villa de Bilbao, entre los días del 11 y 19 de junio, las fuerzas defensoras perdieron a más de 1500 hombres $^{63}$. Obviamente, las bajas mortales acontecidas durante la guerra son otra de las variables que explicarían los números de la represión en la provincia. No en vano, gran parte de las personas ejecutadas por sentencia en consejos de guerra fueron acusadas de desempeñar tareas o cargos de relevancia en el frente.

Las citadas circunstancias explican, en parte al menos, lo que diferentes autores venían manifestando sobre las consecuencias de la represión franquista tras la caída del frente norte, esto es, que «la posguerra — en palabras de Paloma Aguilar- había sido menos dura en el País Vasco que en otras zonas», entre otros factores, debido a que «la represión acabó siendo más leve con los nacionalistas que con otras formaciones políticas» ${ }^{64}$. En efecto, las últimas

Ángel Gondra sobre las gestiones realizadas por el diputado británico George Lansbury a petición de la Delegación del Gobierno de Euzkadi en Londres a fin de que influyera en las autoridades españolas e italianas para que cumplieran lo acordado en el Pacto de Santoña y ayudar de ese modo a los presos.

62 Fusi (1987): 49. Alrededor de 500 de los fallecidos en combate por la defensa de Bizkaia correspondieron a milicianos de batallones santanderinos y asturianos. VV. AA. (2001): 182.

63 Vargas (2007): 147

64 Aguilar (1998): 33. Abundando en esta línea, Jesús Gutiérrez, en su libro sobre la represión franquista en Cantabria, afirmaba que «en Laredo, Santoña y Castro intervinieron tribunales militares procedentes de Bilbao que tenían como consigna imponer penas de muerte a los prisioneros cántabros y fueran más clementes con los responsables políticos singulares del PNV por el hecho de ser católicos y respetuosos con la religión». Gutiérrez (2006): 131. Por su parte, Francisco Vargas Alonso concluía también que «los franquistas, aunque trataron a los nacionalistas vascos con una dureza menos indiscriminada que la que reservaban a los "rojos", procedieron a fusilar a un número reducido de nacionalistas con motivo de dar una lección ejemplificadora a todos los que habían caído en sus manos, así como a la población vasca militante o simpatizante con la causa independentista». Vargas (2001): 340-341. 
investigaciones sobre la incidencia de la represión en los distintos colectivos políticos que perdieron la guerra en Bizkaia corroboran esta tesis. Así, por ejemplo, el porcentaje de ejecutados de todas las opciones políticas tras la caída de Bizkaia fue relativamente proporcional a su grado de implicación en la guerra con la salvedad de los nacionalistas vascos, que fue ostensiblemente menor ${ }^{65}$. En todo caso, hay que subrayar que las labores diplomáticas no evitaron la ejecución y la encarcelación de un buen número personas adscritas al nacionalismo vasco. De hecho, en términos absolutos, el nacionalismo vasco confesional fue la fuerza política vasca con mayor número de procesados por consejo de guerra y la segunda en cuanto al número de ejecutados.

\section{NI EXTERMINIO, NI OASIS}

A decir verdad, no pocas investigaciones sobre la represión franquista han estimado oportuno considerar los términos genocidio, exterminio u holocausto para definir ciertas prácticas coactivas implementadas por el régimen a lo largo de su prolongado ejercicio en el poder ${ }^{66}$. Obviamente, como ha quedado acreditado en el caso vasco, la totalidad de los estudios que categorizan como genocidio u holocausto la represión franquista no merecen la misma consideración, puesto que no todos descansan sobre interpretaciones fundamentadas ni tampoco comparten objetivos meramente académicos ${ }^{67}$.

65 Relación del porcentaje de combatientes y ejecutados vascos tras consejo de guerra en Bizkaia, Cantabria y Asturias. ANV (combatientes - C-: 4,5\%. Ejecutados -E—: $3 \%$ ), Anarquista (C: 7,4 \%. E: 9,4\%), Comunista (C: $20 \%$. E: 10,8 \%), Nacionalista (C: 41,7 \%. E: $1 \%$ ), Socialista (19,5\%. E: $30 \%)$, Republicano (C: 6,6 \%. E: 7,7 \%). Se desconoce la filiación política del 21,1\% de los ejecutados vascos. El estudio consigna como comunistas a los miembros de las Juventudes Socialistas Unificadas (JSU) a fin de otorgar mayor operatividad y eficacia al análisis de los miles de expedientes recopilados. Sin embargo, es patente que una gran parte de los afiliados a las JSU procedentes de las Juventudes Socialistas siguió girando en torno a la órbita del PSOE y de la UGT. Partiendo de la mencionada premisa, entonces, entendemos que los índices de los comunistas y los socialistas tenderían así a equilibrarse. Zubiaga (2017).

66 Marco (2012).

67 Véanse a este respecto, por ejemplo, los trabajos de Antonio Miguez. Miguez es partidario de emplear la perspectiva de estudios de genocidio para analizar los episodios de violencia de retaguardia de los franquistas, si bien es muy crítico con aquellos autores proclives al uso tópico del concepto. Esto es, rechaza las tesis genocidas carentes de dimensión interpretativa porque estas persiguen, exclusivamente, la 
En líneas generales, los razonamientos que demostrarían la existencia de un plan de exterminio y, por lo tanto, la conveniencia de sustantivar como genocida la represión franquista, se han centrado básicamente en argumentos tales como la existencia de un sujeto identificable del enemigo, ciertas manifestaciones de los principales líderes sublevados sobre la necesidad de eliminar físicamente a los adversarios políticos, las prácticas represivas de violencia indiscriminadas implementadas momentos después del golpe del Estado, o el sistemático ocultamiento de pruebas de la represión y la negación del ejercicio de la represión ${ }^{68}$. De igual forma, no todas las tesis que resaltan la característica exterminadora de la represión franquista se refieren exclusivamente al aniquilamiento físico. Así, por ejemplo, se señala que las autoridades militares insurgentes diseñaron entre 1936 y 1948 diversos proyectos «con el objeto de realizar una limpieza política de la sociedad»o, lo que es lo mismo, perseguían el «exterminio político y cultural»y, a su vez, la «conversión forzosa» del adversario político a través de los mecanismos de «eliminación, castigo y aislamiento» ${ }^{69}$.

Al igual que sucede entre los partidarios de sustantivar la represión franquista mediante los citados conceptos, aquellos que cuestionan dichas categorizaciones tampoco forman un colectivo homogéneo, pues cada uno fundamenta sus teorías bajo un prisma interpretativo distinto. En cualquier caso, grosso modo, apuntan que variables tales como la institucionalización de la represión, el descenso escalonado de la intensidad represiva, la vuelta de los exiliados o la genuina concepción jurídica del término genocidio aprobado por la ONU, impiden categorizar como genocida la represión franquista de posguerra.

Por lo que aquí nos interesa, entiendo que los estudios que disponemos en la actualidad constatan que el ejercicio de la represión de posguerra en el País Vasco no puede ser catalogado como genocida o exterminadora puesto que la política coactiva fue prioritariamente dirigida a la neutralización y al control de los adversarios políticos más que a su completa aniquilación física. Como ya ha quedado expuesto en varios trabajos aquí citados, la primera fase de la represión, feroz y agresiva, centrada en la socialización del terror y

«equiparación de su significado con sucesos muy graves de matanzas colectivas»y, por consiguiente, se limitan a atribuir un carácter enfático al término. Miguez (2014) y (2012).

68 La abundancia de fosas comunes dispersas por todo el territorio sería uno de los mayores exponentes del deseo de ocultar los cadáveres con el fin de que nada de lo sucedido transcendiera (Miguez, 2012).

69 Gómez y Marco (2011): 66. 
dirigida al rápido control de los resortes del poder, fue en el País Vasco paulatinamente sustituida por otro tipo de violencia reorientada tanto al férreo control social así como a la "conversión» de parte de los vencidos. De forma que, a la altura de 1940, con la victoria militar asegurada y con la oposición política paralizada, el régimen comenzó a articular medidas de revisión de penas que a la postre posibilitarían la excarcelación de la mayor parte de los presos de la guerra ${ }^{70}$. En cualquier caso, baste señalar que la paulatina excarcelación de los presos vascos, mayormente tras sufrir un cautiverio medio cercano a los cinco años, no vino aparejada de política de reconciliación alguna. Esto supone que si bien los mecanismos represivos disminuyeron su intensidad coactiva, tal hecho fue paralelo con su mantenimiento activo, cumpliendo eficazmente su cometido: castigo de la disidencia y control social por amenaza de castigo.

De la misma manera, no podemos pasar por alto los números que revela el actual mapa geográfico de la represión franquista en España. Los índices de ejecutados demuestran que el País Vasco fue unas de las comunidades menos castigadas tras la victoria militar de las tropas rebeldes. Este hecho, obviamente, no implica, ni mucho menos, que buena parte de los vencidos vascos sorteará los rigores de la represión. La implementación de una política represiva múltiple fue en el País Vasco, al igual que en el resto de los territorios ocupados, inherente al ejercicio del poder del «nuevo Estado». Buena prueba de ello son las ejecuciones, pero también los miles de procesados por procedimientos sumarísimos de urgencia, la ingente cantidad de funcionarios depurados de sus puestos de trabajos, otros tantos sancionados con penas económicas o los más de 79000 exiliados vascos ${ }^{71}$. Igualmente, la población vasca no pudo escapar de las nefastas consecuencias del intervencionismo estatal, del hambre, del racionamiento ni del mercado negro.

A modo de cierre, concluyo que es la propia naturaleza de la investigación histórica, minuciosa y provisional en tanto que siempre atenta a nuevos descubrimientos e interpretaciones, la que impide a los historiadores presentar como finiquitado el estudio de todo acontecimiento del pasado por más que este haya sido objeto de innumerables trabajos y debates académicos. Algo de esto sucede con el periodo histórico que aquí nos ocupa. Es indudable que el avance de la

70 El régimen activó y aceleró sobremanera los instrumentos jurídicos tendentes a la excarcelación de los reclusos de la guerra con la promulgación de la orden de 25 de enero de 1940, según la cual instauraba un procedimiento de revisión y examen de las penas falladas por los tribunales militares desde el inicio de la sublevación militar.

71 Ostolaza (1996); Badiola (2010), y Casquete et al. (2012): 447-449. 
historiografía nos permite hoy disponer de interpretaciones solventes que explican buena parte de los acontecimientos decisivos que acontecieron durante la guerra y la posguerra en Euskadi. Sin embargo, no es menos cierto que aún siguen existiendo lagunas historiográficas de envergadura por cubrir y no pocas interpretaciones por revisar. Con todo, opino que los retos del investigador social no se limitan únicamente a esclarecer con rigor las importantes incógnitas historiográficas existentes, sino que en la coyuntura actual, donde la memoria tiende a confundirse con la historia, su tarea debe servir también para reivindicar la historia académica, aquella comprometida con la deontología de la profesión y la honestidad intelectual, como única herramienta capaz de ofrecer una interpretación cabal y desprejuiciada del pasado.

\section{Bibliografía}

Aguilar, P. (1998). La peculiar evocación de la guerra civil por el nacionalismo vasco. Cuadernos de Alzate, 18, 21-40.

Aizpuru, M. (2007). El otoño de 1936 en Guipúzcoa. Los fusilamientos de Hernani. Zarautz: Alberdania.

Anderson, P. (2014). Escándalo y diplomacia. La utilización de los consejos de guerra para mantener la represión franquista durante la guerra civil. En P. Anderson y M. A. del Arco. Lidiando con el pasado. Represión y memoria de la guerra civil y el franquismo (pp. 83-100). Granada: Comares.

Badiola, A. (2010). La depuración de los funcionarios públicos en la Diputación Provincial de Vizcaya. Espacio, Tiempo y Forma, Serie Historia Contemporánea, 22, 383-401.

Barruso, P. (2005). Violencia politica y represión en Guipúzcoa durante la guerra civil y el primer franquismo (1936-1945). San Sebastián: Hiria.

Calvo, C. (1995). Los límites del consenso franquista en Guipúzcoa. Las actitudes del nacionalismo vasco 1936-1942. Comunicación presetada en II Encuentro de Investigadores del Franquismo, (Alicante, 11, 12 y 13 de mayo de 1995) (vol. 2, pp. 29-36). Alicante: Diputación Provincial de Alicante.

Casquete, J. (2009). En el nombre de Euskal Herria. La religión política del nacionalismo vasco radical. Madrid: Tecnos.

— De Pablo, S., De la Granja, J. L. y Mees, L. (coords.) (2012). Diccionario ilustrado de símbolos del nacionalismo vasco. Madrid: Tecnos.

Castells, L. y Molina, F. (2013). Bajo la sombra de Vichy. El relato del pasado reciente en la Euskadi actual. Ayer, 89, 215-227.

Centro de Información Católica Internacional (1940). El clero y los católicos vasco-separatistas y el Movimiento Nacional. Madrid.

Cossio, F. (1937). Guerra de salvación. Valladolid: Librería Santanrén.

De la Granja, J. L. (1987). El nacionalismo vasco ante la guerra civil. En VV. AA. La Guerra Civil en el País Vasco 50 años después (pp. 53-88). Bilbao: UPV-EHU. 
- (1990). República y guerra civil en Euskadi. Del pacto de San Sebastián al de Santoña. Oñate: IVAP.

— y De Pablo, S. (dir.) (2009). Guía de fuentes documentales y bibliográficas sobre la Guerra Civil en el País Vasco. San Sebastián: Departamento de Cultura del Gobierno Vasco.

De Pablo, S. (1990). El PNV alavés en julio de 1936. Polémica actuación ante la victoria de los sublevados. Historia 16, 166, 27-38.

- (2003). La guerra civil en el País Vasco: ¿un conflicto diferente? Ayer, 50, 115-141.

— , Goñi, J. y López de Maturana, V. (2013). La diócesis de Vitoria. 150 años de historia (1862-2012). Vitoria: Editorial Eset. Obispado de Vitoria.

— , Mees, L. y Rodriguez, J. A. (2001). El péndulo patriótico. Historia del Partido Nacionalista Vasco. Tomo II, 1936-1979, Barcelona: Crítica.

Egaña, I. (dir.). (1998-1999). 1936, Guerra civil en Euskal Herria. Represión en Bizkaia. Andoain: Aralar.

- (2011a). Frankismoa Donostian. Las victimas del genocidio franquista en Donostia. San Sebastián: Genozidioaren Biktimen Elkartea.

- (2011b). El franquismo en Euskal Herria. La solución final. Andoain: Euskal memoria.

Espinosa, F. (1999). La memoria del fiscal del ejército de ocupación. En Actas del IV Encuentro de Investigadores del Franquismo: Tiempos de silencio (Valencia, 17-19 de noviembre de 1999) (pp. 34-39). Valencia: Fundació d'Estudis i Iniciatives Sociolaborals.

Espinosa, F. (2009). Sobre la represión franquista en el País Vasco, Historia Social, 63, 58-76. Espinosa, F. (2010). La represión franquista: un combate por la historia y la memoria. En F. Espinosa et al. Violencia roja y azul. España, 1936-1950 (pp. 17-80). Barcelona: Crítica.

Fernández, G. (2014). Ecos de la Guerra Civil. La glorificación del gudari en la génesis de la violencia de ETA (1936-1968), Bulletin d'histoire contemporaine de l'Espagne, 49, 247-261.

- y López, R. (2012). Sangre, votos, manifestaciones: ETA y el nacionalismo vasco radical. 1958-2011. Madrid: Tecnos.

Fraser, R. (2001) [1979]. Recuérdalo tú y recuérdalo a otros. Barcelona: Crítica.

Fusi, J. P. (1987). La Guerra Civil en el País Vasco: Una perspectiva general. En VV.AA. La Guerra Civil en el País Vasco 50 años después (pp. 43-50). Bilbao: UPV-EHU.

Garmendia, J. M. y González, M. (1993). Crecimiento económico y actitudes políticas de la burguesía vasca, en la posguerra. En VV. AA. España franquista. Causa General y Actitudes Sociales ante la Dictadura (pp. 179-195). Albacete: Ediciones Universidad de Castilla La-Mancha.

Gil, P. (2004). La noche de los generales. Militares y represión en el régimen de Franco. Barcelona: Ediciones B.

- (2010). Derecho y ficción: la represión judicial militar. En F. Espinosa. Violencia roja y azul, 1936-1950 (pp. 251-368). Barcelona: Crítica.

Gómez, G. y Marco, J (2011). La obra del miedo. Violencia y sociedad en la España franquista (1936-1950). Barcelona: Peninsula.

Gómez Calvo, J. (2014). Matar, purgar, sanar. La represión franquista en Álava. Madrid: Tecnos. Gutiérrez, J. (2006). Guerra civil en los pueblos de Cantabria y Castilla. Libros en red. Irujo, X. (2015). Genocidio en Euskal Herria. 1936-1945. Pamplona: Nabarralde. Jackson, G. (2005) [1965]. La República española y la guerra civil. Madrid: RBA. 
Judt, T. (2006). Posguerra. Una historia de Europa desde 1945. Madrid: Taurus.

Juliá, S. (1999). De guerra contra el invasor a guerra fratricida. En S. Juliá (coord.). Víctimas de la guerra civil (pp.11-56). Madrid: Temas de hoy.

Marco, J. (2012). Genocidio y genocide studies: definición y debates. Hispania Nova, 10, Disponible en: http://hispanianova.rediris.es/10/dossier/10d002.pdf.

Míguez, A. (2012). Nuestro pasado presente: práctica genocida y franquismo. Hispania Nova, 10, Disponible en: http://hispanianova.rediris.es/10/dossier/10d010.pdf.

- (2014). La genealogía genocida del franquismo. Violencia, memoria e impunidad, Madrid: Abada.

Molina, F. (2014). Lies of our fathers: Memory and Politics in the Basque Country Under the Franco Dictatorship. 1936-1968. Jounal of Contemporary History, 49, 296-319. Disponible en: https://doi.org/10.1177/0022009413515538.

— y Pérez, J. A. (eds.) (2015). El peso de la identidad: mitos y ritos de la historia vasca. Madrid: Marcial Pons.

Muñoz Molina, A. (2013). Todo lo que no era sólido. Barcelona: Seix Barral.

Núnez, X. M. (2007). Los nacionalistas vascos durante la guerra civil. Una cultura diferente. Historia Contemporánea, 35, 559-599.

Olazábal, C. M. (2009). Pactos y traiciones. Los archivos secretos de la guerra en Euzkadi. Bilbao: Atxular Atea. (Tres tomos).

Ostolaza, M. (1996). El garrote de la depuración. Maestros vascos en la guerra civil y el primer franquismo (1936-1945). San Sebastián: Ibaeta Pedagogía.

Pérez, J. A. (2013). Historia (y memoria) del antifranquismo en el País Vasco. Cuadernos de Historia Contemporánea, 35, 41-62. Disponible en: https://doi.org/10.5209/rev_ CHCO.2013.v35.42648.

Prada, J. (2010). La España masacrada. La represión franquista de guerra y posguerra. Madrid: Alianza.

Preston, P. (2011). El holocausto español. Madrid: Debate.

Rieff, D. (2016). In Praise of forgetting: Historical memory and its ironies. London: Yale University Press.

Rivera, A. (2004). Cuando la mala historia es peor que la desmemoria. Acerca de los mitos de la historia contemporánea vasca. El valor de la palabra. Hitzaren balioa, 4, 41-72.

Rivera, A. y Gómez, J. (2015). Siempre se recuerda lo que nunca ocurrió: represión franquista y memoria colectiva en el País Vasco. Comunicación presentada en el Colóquio Internacional sobre Violência Política no Século XX. (Lisboa, 12-14 de marzo de 2015).

Rodrigo, J. (2003). Los campos de concentración franquistas. Entre la historia y la memoria. Madrid: Siete mares.

- (2008). Hasta la raíz. Violencia durante la guerra civily la dictadura franquista. Madrid: Alianza Editorial.

Rodríguez, M. L. (1981). El cardenal Gomá y la guerra de España. Aspectos de la gestión pública del Primado 1936-1939. Madrid: Consejo Superior de Investigaciones Científicas.

Ruiz, J. (2005). A Spanish genocide? Reflections on the Francoist Repression after Spanish Civil War. Contemporary European HIstory, 14 (2), 171-191. Disponible en: https:// doi.org/10.1017/S0960777305002304. 
Sole, J. y Villarroya, J. (1999). Mayo de 1937-Abril de 1939. En S. Juliá (coord.). Víctimas de la guerra civil (pp. 187-276). Madrid: Temas de hoy.

Tebib A. (1942). La conquista de Vizcaya. Valladolid: Librería Santaren.

Uriarte, E. (2013). El tiempo de los canallas: la democracia ante el fin de ETA. Vitoria: Ikusager.

Vargas, F. M. (2001). El Partido Nacionalista Vasco en guerra. Euzko Gudarostea. Vasconia, 31, 305-343.

- (2007). Bilbao, la última resistencia. La batalla de Archanda-santo. Bidebarrieta. Revista de Humanidades y Ciencias Sociales, 18, 131-150.

Vega, S. (2011). La politica del miedo. El papel de la represión en el franquismo. Barcelona: Crítica.

VV. AA. (1998). Espetxean 1937-1942. Semilla de libertad. Bilbao: Fundación Sabino Arana. VV. AA. (2001). Crónica de la Guerra Civil de 1936-1937 en la Euzkadi penínsular. Segunda parte. La batalla de Bilbao y el final de la guerra en el norte, Tomo V. Oihartzun: Sendoa.

Zubiaga, E. (2016). Lo que no pudo hacer Zumalacárregui, lo vamos a hacer nosotros. El castigo, la conquista de almas y las actitudes sociales en Bizkaia durante la inmediata posguerra. En A. Miguez (coord.). Ni verdugos ni victimas. Actitudes sociales ante la violencia, del franquismo a la dictadura argentina (pp. 79-99). Granada: Comares.

- (2017). La huella del terror franquista en Bizkaia. Jurisdicción militar, políticas de captación y actitudes sociales (1937-1945). Bilbao: Universidad del País Vasco. 